\title{
CFD simulation on the gasification of asphalt water slurry in an entrained flow gasifier
}

\author{
Lan Xingying*, Zhong Hanbin and Gao Jinsen \\ State Key Laboratory of Heavy Oil Processing, China University of Petroleum, Beijing 102249, China \\ (C) China University of Petroleum (Beijing) and Springer-Verlag Berlin Heidelberg 2014
}

\begin{abstract}
Gasification technology is suggested to utilize asphalt particles, which are produced in the heavy oil deep separation process of using coupled low temperature separation of solvent and post extraction residue. In this work, the asphalt particles were first slurried with water and then gasified to produce synthesis gas. The gasification process of asphalt water slurry in an entrained flow gasifier was simulated using a three-dimensional computational fluid dynamics (CFD) model based on an EulerianLagrangian method. The trajectories and residence time of asphalt particles, and the reaction rates, gas species distribution, temperature field and carbon conversion in the entrained flow gasifier were obtained. The predicted results indicated that the asphalt water slurry was a good feedstock for gasification. Moreover, the effects of particle size, oxygen equivalence ratio, and mass content of asphalt particles on the gasification performance of asphalt water slurry were investigated. These results are helpful for industrial application of asphalt water slurry gasification technology.
\end{abstract}

Key words: Asphalt particles, water slurry, gasification, entrain flow gasifier, CFD

\section{Introduction}

Zhao et al (2009) have proposed a novel deep solvent deasphalting (SDA) method for heavy oils. This method can greatly improve the yield and quality of deasphalted oil, and simultaneously produce solid asphalt particles amounting to about $20 \mathrm{wt} \%$ of the feedstock. Efficient low emission utilization of these asphalt particles is critical for commercial application of the deep SDA method. The integrated deasphalting-gasification process may be a good choice to utilize the asphalt particles. In the existing deasphaltinggasification unit, asphalt is fed into the gasifier as a liquid. If the asphalt particles are treated to be gasification feedstock in the existing deasphalting-gasification unit, they must be heated at a high temperature to meet the viscosity limits of the pumping system. Generally, the softening point of asphalt should be below $100{ }^{\circ} \mathrm{C}$ because of the constraints of the feeding system and chemical decomposition and condensation of asphalt in the existing deasphaltinggasification unit (Xu, 2010). Unfortunately, the softening point of asphalt particles obtained by the deep SDA method is about $180^{\circ} \mathrm{C}$. Therefore, it is not feasible to utilize the asphalt particles in the existing gasification unit. Currently, coal-water slurry (CWS) gasification technology is widely used. With the similar properties to coal, the asphalt particles can be made into an asphalt water slurry. Referring to the CWS gasification process, the gasification of asphalt slurry may be an effective way to settle the feeding problem and

*Corresponding author. email: Lanxy@cup.edu.cn

Received September 1, 2013 utilize the asphalt particles with a high softening point.

Nowadays, computational fluid dynamics (CFD) simulation is becoming an efficient method for developing and improving gasification technology, and it is especially widely used in entrained flow coal slurry gasifiers. In most previous CFD simulations, the coal slurry gasification process is divided into several simple subprocesses: coal slurry atomization, water evaporation, coal pyrolysis, and homogeneous and heterogeneous reactions of coal char particles (Sun et al, 2012). Usually, the coal slurry is assumed to be atomized completely, and a Langrangian particle tracking method is used to describe the detailed gasification process of coal slurry particles. The standard $k-\varepsilon$ turbulence model or realizable $k-\varepsilon$ turbulence model is used to evaluate the gas flow. The previous simulated results show that CFD modeling can predict the overall performance of the coal gasification process and optimize the operation parameters. For example, Sun et al (2012) have numerically predicted the flow field, temperature and species concentration distributions inside an industrial opposed multi-burner entrained-flow gasifier, and investigated the effects of the slurry concentration and oxygen/coal ratio on the gasifier performance. Wu et al (2010) have employed CFD simulation to compare the performance of GE gasifiers (GE gasifier is a specific style of gasifier, which is invented by General Electric (GE) corporation) and staged coal slurry gasifiers, and found that the mixing process in the staged gasifier was better than that in a GE gasifier due to the existence of secondary oxygen flow. Chen et al (2001) have studied the influence of design parameters such as the throat diameter ratio and swirl ratio of burner injection on the performance of a two-stage air blown 
gasifier, and concluded that the throat diameter was critical for the gas flow field in the gasifier.

Because of the similarity of the gasification process of asphalt water and coal water slurries, CFD simulation will be applied to predict the gasification characteristics of asphalt water slurry in an entrained flow gasifier in the present paper. Moreover, the effects of operating parameters, such as particle size, oxygen equivalence ratio, and the concentration of asphalt particles slurry, on the gasification performance of asphalt water slurry will be investigated.

\section{CFD Model}

For the gasification of asphalt water slurry in an entrained flow gasifier, the complex physical and chemical processes mainly include the atomization of the slurry, the evaporation and boiling of water, the pyrolysis of asphalt, heterogeneous reactions, and homogeneous reactions, as shown in Fig. 1.

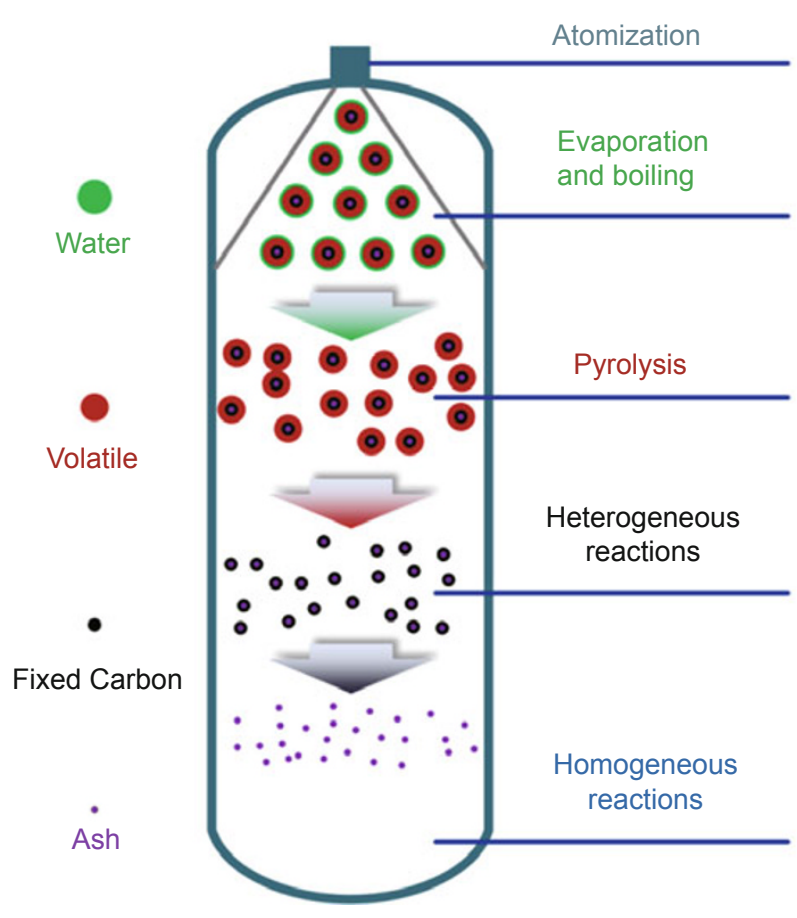

Fig. 1 The gasification process of asphalt water slurry

\subsection{Atomization of water slurry}

After the asphalt slurry is fed into the gasifier, it is firstly atomized into fine droplets. The slurry is considered to be fully atomized, and the size distribution of droplets is assumed to be same as that of the asphalt particles in the slurry. The size distribution of droplets can be fitted by the Rosin-Rammler distribution.

$$
Y_{\mathrm{d}}=\exp \left(-\left(d_{\mathrm{p}} / d_{\mathrm{av}}\right)^{n}\right)
$$

where $Y_{\mathrm{d}}$ is the mass fraction of droplets with the diameter greater than $d_{\mathrm{p}}, d_{\mathrm{av}}$ and $\mathrm{n}$ is the mean diameter and spread parameter, respectively.

\subsection{Evaporation and boiling of water}

After the atomization of the slurry, the droplets are quickly heated. When the temperature of droplets reaches the vaporization temperature, the droplets begin to evaporate until the temperature reaches the boiling point. The evaporation rate is governed by the bulk steam partial pressure and steam saturation pressure at the surface of droplets.

$$
\frac{\mathrm{d} m_{\mathrm{w}}}{\mathrm{d} t}=-k_{\mathrm{c}}\left(\frac{P_{\mathrm{sat}}\left(T_{\mathrm{p}}\right)}{R T_{\mathrm{p}}}-X_{\mathrm{w}} \frac{P}{R T}\right) A_{\mathrm{p}} M_{\mathrm{w}}
$$

where $P_{\text {sat }}$ is the saturated vapor pressure at the temperature $T_{\mathrm{p}}, T_{\mathrm{p}}$ is the temperature of droplets, $X_{\mathrm{w}}$ is the local bulk mole fraction of water, and $T$ is the local bulk temperature in the gas. The mass transfer coefficient $k_{\mathrm{c}}$ is calculated from the Sherwood number correlation (Ranz and Marshall, 1952a; 1952b):

$$
k_{\mathrm{c}}=\operatorname{Sh}_{\mathrm{AB}} \frac{D_{i, \mathrm{~m}}}{d_{\mathrm{p}}}=\left(2.0+0.6 \operatorname{Re}^{1 / 2} \mathrm{Sc}^{1 / 3}\right) \frac{D_{i, \mathrm{~m}}}{d_{\mathrm{p}}}
$$

When $T_{\mathrm{p}}$ reaches the boiling point, a boiling rate equation is applied (Kuo, 1986):

$$
\frac{\mathrm{d}\left(d_{\mathrm{p}}\right)}{\mathrm{d} t}=\frac{4 \lambda_{\mathrm{g}}}{\rho_{\mathrm{p}} c_{\mathrm{g}} d_{\mathrm{p}}}(1+0.23 \sqrt{\operatorname{Re}}) \ln \left[1+\frac{c_{\mathrm{p}}\left(T-T_{\mathrm{p}}\right)}{h_{\mathrm{w}}}\right]
$$

where $c_{\mathrm{g}}$ is the heat capacity of the gas, $\lambda_{\mathrm{g}}$ is the thermal conductivity of the gas.

\subsection{Pyrolysis of asphalt}

The pyrolysis of asphalt is assumed to include two continuous steps: the devolatilization of asphalts and the decomposition of volatiles.

Reaction 1:

$$
\text { asphalts } \rightarrow \text { volatiles }+ \text { petroleum coke }
$$

Reaction 2:

$$
\begin{aligned}
& \text { volatiles } \rightarrow \alpha_{1} \mathrm{H}_{2}+\alpha_{2} \mathrm{CH}_{4}+\alpha_{3} \mathrm{CO}+\alpha_{4} \mathrm{C}_{6} \mathrm{H}_{6} \\
& \quad+\alpha_{5} \mathrm{CO}_{2}+\alpha_{6} \mathrm{H}_{2} \mathrm{~S}+\alpha_{7} \mathrm{~N}_{2} \\
& \sum_{i=1}^{7} \alpha_{i}=1
\end{aligned}
$$

The composition of volatiles is determined by the proximate and ultimate analysis results of asphalt. Gong et al (2003) have proposed a two-stage first-order model to describe the pyrolysis of asphalt. The kinetics of pyrolysis is as follows:

$$
\frac{\mathrm{d} x}{\mathrm{~d} t}=k_{0}\left(x_{\infty}-x\right) \exp \left(-\frac{E}{R T}\right)
$$

where $x$ is the mass fraction of produced volatiles, $x_{\infty}$ is the final yield of volatiles. For $T<698 \mathrm{~K}, k_{0}=430 \mathrm{~L} / \mathrm{min}$ and $E=$ 
$28.0 \mathrm{~kJ} / \mathrm{mol}$, for $T \geq 698 \mathrm{~K}, k_{0}=5.0 \times 10^{8} \mathrm{~L} / \mathrm{min}$ and $E=120.0$ $\mathrm{kJ} / \mathrm{mol}$.

\subsection{Heterogeneous reactions}

The heterogeneous reactions in the gasification process include the reactions of petroleum coke with oxygen, carbon dioxide, and steam. The rate of heterogeneous reactions is determined by the diffusion and intrinsic chemical reaction rate:

$$
\begin{aligned}
& \bar{r}_{j, \mathrm{~s}}=A_{\mathrm{p}} \eta_{\mathrm{r}} Y_{j} r_{j, \mathrm{~s}} \\
& r_{j, \mathrm{~s}}=r_{\mathrm{kin,}}\left(P-\frac{r_{j, \mathrm{~s}}}{D_{j, \mathrm{~s}}}\right)^{n} \\
& D_{j, \mathrm{~s}}=C_{j, \mathrm{~s}} \frac{\left[\left(T_{\mathrm{p}}+T\right) / 2\right]^{0.75}}{d_{\mathrm{p}}} \\
& r_{\mathrm{kin}, \mathrm{r}}=A_{0} T^{\beta} \exp (-E / R T)
\end{aligned}
$$

where $\bar{r}_{j, s}$ is the rate of surface species depletion, $A_{\mathrm{p}}$ is the surface area, $Y_{j}$ is the mass fraction of surface species $j$ in the particle, $r_{j, s}$ is the rate of surface species reaction per unit area, $n$ is the reaction order, $D_{j, s}$ is the diffusion rate coefficient, $C_{j, s}$ is the diffusion rate constant.

Harris and Smith (1991) investigated the intrinsic reactivity of petroleum coke with carbon dioxide, steam and oxygen. The pre-exponential factor $A_{0}$ and activation energy $E$ for each heterogeneous reaction are listed in Table 1.

Table 1 Heterogeneous reactions and kinetic parameters

\begin{tabular}{ccccc}
\hline Reaction & $\begin{array}{c}A_{0}, \\
\mathrm{~kg} /\left(\mathrm{m}^{2} \cdot \mathrm{s} \cdot \mathrm{Pa}^{n}\right)\end{array}$ & $\begin{array}{c}E \\
\mathrm{~J} / \mathrm{kmol}\end{array}$ & $\begin{array}{c}\Delta H_{\mathrm{r}} \\
\mathrm{kJ} / \mathrm{mol}\end{array}$ \\
\hline Reaction 3: $\quad \mathrm{C}+0.5 \mathrm{O}_{2} \rightarrow \mathrm{CO}$ & 1.7016 & $1.55 \times 10^{8}$ & 0.64 & -111 \\
Reaction 4: $\quad \mathrm{C}+\mathrm{CO}_{2} \rightarrow 2 \mathrm{CO}$ & 0.0253 & $2.14 \times 10^{8}$ & 0.65 & +172 \\
Reaction 5: $\mathrm{C}+\mathrm{H}_{2} \mathrm{O} \rightarrow \mathrm{CO}+\mathrm{H}_{2}$ & 0.4114 & $2.38 \times 10^{8}$ & 0.56 & +131 \\
\hline
\end{tabular}

\subsection{Homogeneous reactions}

The homogeneous reactions include the combustion, water-gas shift, and methane-steam reactions.

$$
\begin{array}{llr}
\text { Reaction 6: } & \mathrm{C}_{6} \mathrm{H}_{6}+3 \mathrm{O}_{2} \rightarrow 6 \mathrm{CO}+3 \mathrm{H}_{2} & -746 \mathrm{MJ} / \mathrm{kmol} \\
\text { Reaction 7: } & \mathrm{C}_{6} \mathrm{H}_{6}+6 \mathrm{H}_{2} \mathrm{O} \rightarrow 6 \mathrm{CO}+9 \mathrm{H}_{2} & +705 \mathrm{MJ} / \mathrm{kmol} \\
\text { Reaction 8: } & \mathrm{CO}+0.5 \mathrm{O}_{2} \rightarrow \mathrm{CO}_{2} & -283 \mathrm{MJ} / \mathrm{kmol} \\
\text { Reaction 9: } & \mathrm{H}_{2}+0.5 \mathrm{O}_{2} \rightarrow \mathrm{H}_{2} \mathrm{O} & -242 \mathrm{MJ} / \mathrm{kmol} \\
\text { Reaction 10: } & \mathrm{CH}_{4}+0.5 \mathrm{O}_{2} \rightarrow \mathrm{CO}+2 \mathrm{H}_{2} & -37.5 \mathrm{MJ} / \mathrm{kmol} \\
\text { Reaction 11: } & \mathrm{CH}_{4}+\mathrm{H}_{2} \mathrm{O} \Leftrightarrow \mathrm{CO}+3 \mathrm{H}_{2} & +203 \mathrm{MJ} / \mathrm{kmol} \\
\text { Reaction 12: } & \mathrm{CO}+\mathrm{H}_{2} \mathrm{O} \Leftrightarrow \mathrm{CO}_{2}+\mathrm{H}_{2} & -41.1 \mathrm{MJ} / \mathrm{kmol}
\end{array}
$$

In the complex turbulent reaction flow, the net homogeneous reaction rate $r_{i, \text { gas }}$ is determined by the minimum value of chemical reaction rate $r_{i, \text { chem }}$ and turbulent mixing rate $r_{i, \text { tur }}$. The Arrhenius expression is applied to describe the chemical reaction rate $r_{i, \text { chem }}$, and the eddy-dissipation model is used to determine the turbulent mixing rate $r_{i, \text { tur }}$ (Magnussen and Hjertager, 1977).

$$
\begin{gathered}
r_{i, \text { chem }}=A_{0} T^{\beta} \exp (-E / R T) \prod_{j=1}^{N}\left[C_{j, r}\right]^{n_{j}} \\
r_{i, \text { tur }}=\min \left[v_{i, r}^{\prime} M_{w, i} A \rho \frac{\varepsilon}{k} \min _{R}\left(\frac{Y_{R}}{v_{R, r}^{\prime} M_{\mathrm{w}, R}}\right), v_{i, r}^{\prime} M_{\mathrm{w}, i} A B \rho \frac{\varepsilon}{k} \frac{\sum_{P} Y_{P}}{\sum_{j}^{N} v_{j, r}^{\prime \prime} M_{\mathrm{w}, j}}\right] \\
r_{i, \text { gas }}=\min \left(r_{i, \text { chem }}, r_{i, \text { tur }}\right)
\end{gathered}
$$

where $v_{i, r}^{\prime}$ is the stoichiometric coefficient for reactant $i$ in reaction $r, v_{i, r}^{\prime \prime}$ is the stoichiometric coefficient for product $i$ in reaction $r, Y_{P}$ is the mass fraction of any product species, $Y_{R}$ is the mass fraction of a specific reactant, $A$ is an empirical constant equal to 4.0 , and $B$ is an empirical constant equal to
0.5 . The pre-exponential factor $A_{0}$ and activation energy $E$ for each homogeneous reaction are shown in the reaction rate expressions in Table 2. The methane-steam (Reaction 11) and water-gas shift (Reaction 12) are assumed to reach chemical equilibrium at all locations, and the forward reaction rate 
Table 2 Homogeneous reactions and kinetic parameters

\begin{tabular}{|c|c|}
\hline Reaction rate expression, $\mathrm{kmol} /\left(\mathrm{m}^{3} \cdot \mathrm{s}\right)$ & Reference \\
\hline \multicolumn{2}{|l|}{$r_{6}=$ Eddy-dissipation only } \\
\hline$r_{7}=3.0 \times 10^{8} \exp \left(-\frac{1.26 \times 10^{8}}{8314 T}\right)\left[\mathrm{C}_{6} \mathrm{H}_{6}\right]\left[\mathrm{H}_{2} \mathrm{O}\right]$ & (Jones and Lindstedt, 1988) \\
\hline$r_{8}=1.0 \times 10^{17.6} \exp \left(-\frac{1.67 \times 10^{8}}{8314 T}\right)[\mathrm{CO}]\left[\mathrm{H}_{2} \mathrm{O}\right]^{0.5}\left[\mathrm{O}_{2}\right]^{0.25}$ & (Westbrook and Dryer, 1981) \\
\hline$r_{9}=2.5 \times 10^{16} T^{-1} \exp \left(-\frac{1.68 \times 10^{8}}{8314 T}\right)\left[\mathrm{H}_{2}\right]^{0.5}\left[\mathrm{O}_{2}\right]^{2.25}\left[\mathrm{H}_{2} \mathrm{O}\right]^{-1}$ & (Jones and Lindstedt, 1988) \\
\hline$r_{10}=4.4 \times 10^{11} \exp \left(-\frac{1.26 \times 10^{8}}{8314 T}\right)\left[\mathrm{CH}_{4}\right]^{0.5}\left[\mathrm{O}_{2}\right]^{1.25}$ & (Jones and Lindstedt, 1988) \\
\hline$r_{11}=3.0 \times 10^{8} \exp \left(-\frac{1.26 \times 10^{8}}{8314 T}\right)\left(\left[\mathrm{CH}_{4}\right]\left[\mathrm{H}_{2} \mathrm{O}\right]-[\mathrm{CO}]\left[\mathrm{H}_{2}\right]^{3} / K_{11}\right)$ & (Jones and Lindstedt, 1988) \\
\hline$K_{11}=8.74 \times 10^{12} \exp \left(-\frac{26533}{T}\right)$ & \\
\hline$r_{12}=2.34 \times 10^{10} \exp \left(-\frac{2.883 \times 10^{8}}{8314 T}\right)\left([\mathrm{CO}]\left[\mathrm{H}_{2} \mathrm{O}\right]-\left[\mathrm{CO}_{2}\right]\left[\mathrm{H}_{2}\right] / K_{12}\right)$ & (Bustamante et al, 2005) \\
\hline$K_{12}=0.0265 \exp \left(\frac{3968}{T}\right)$ & \\
\hline
\end{tabular}

Note: [ ] represents the concentration of species.

and equilibrium constant are used to calculate the chemical reaction rate.

\subsection{Governing equations and solution methods}

Because of a low volume fraction of asphalt particles in entrained flow gasifiers, the discrete phase model based on an Eulerian-Lagrangian approach is employed in this work to calculate the trajectories of asphalt particles. The gas phase is regarded as a continuum, while the particles are tracked in a Lagrangian procedure by integrating the force balance on the particles. The realizable $k-\varepsilon$ model is used to describe the turbulent behavior in the gasifier. The radiation heat transfer is described by the $\mathrm{P}-1$ radiation model. The governing equations for the gas and particle phases are summarized in Table 3.

The governing equations are solved sequentially using the finite-volume method (Patankar, 1980) on Fluent 6.3.26. The velocity correction is realized to satisfy continuity through the SIMPLE method (Patankar, 1980) which couples velocity and pressure. The discretization scheme for the convective terms and species is the second-order upwind method. The standard scheme is used for pressure discretization, and the first-order upwind scheme is used for turbulent kinetic energy and dissipation rate.

\section{Model validation}

Watanabe et al (2002) have investigated the gasification process of orimulsion which is a bitumen-in-water emulsified fuel comprised of approximately $70 \mathrm{wt} \%$ bitumen. The asphalt-in-water slurry has similar physical and chemical properties to orimulsion. Therefore, the experimental data of orimulsion gasification in an entrained flow gasifier can be used to validate the CFD model for the gasification of asphalt water slurry. The experimental setup of the orimulsion gasification is shown in Fig. 2, and the properties of the orimulsion are shown in Table 4 (Watanabe et al, 2002).

The operating pressure is $1.9 \mathrm{MPa}$, and the flow rate of the orimulsion and oxygen are $85 \mathrm{~kg} / \mathrm{h}$ and $77 \mathrm{~kg} / \mathrm{h}$, respectively, which correspond to the oxygen equivalence ratio (the ratio of actual oxygen to stoichiometric oxygen) of 0.40 . The size distribution of droplets after atomization was determined by the micro-explosion phenomenon visualization experiment (Watanabe et al, 2002), and it followed a Rosin-Rammler distribution with $d_{\mathrm{av}}=30 \mu \mathrm{m}$ and $n=1.2$ (Watanabe et al, 2002). Just one quarter of the gasifier was simulated considering the symmetry of gasifier geometry and computational cost. The grid number was determined to be 127,200 through the grid-independency study. The heat flux at the wall was determined from experimental data (Ashizawa et al, 2005). The mass-flow inlet boundary was defined at the inlet of the gasifier, and the gasifier outlet was set as pressure outlet boundary.

Fig. 3 compares the predicted species mole fraction and temperature at the outlet of the gasifier with experimental data. The good agreement between simulation and experimental results demonstrates that the developed CFD model is able to capture the main characteristics of the orimulsion gasification process in an entrained flow gasifier. Considering the similarity of gasification process of the 
Table 3 Governing equations for gas and particle phases

\begin{tabular}{|c|c|c|}
\hline Items & Governing equations & \\
\hline \multicolumn{3}{|l|}{ For gas phase } \\
\hline Mass & $\frac{\partial}{\partial x_{i}}\left(\bar{\rho} \tilde{\boldsymbol{u}}_{i}\right)=S_{\mathrm{m}}$ & $(14)$ \\
\hline Momentum & $\frac{\partial}{\partial x_{i}}\left(\bar{\rho} \tilde{\boldsymbol{u}}_{i} \tilde{\boldsymbol{u}}_{j}\right)=-\frac{\partial P}{\partial x_{j}}+\frac{\partial}{\partial x_{j}} \mu\left(\frac{\partial \tilde{\boldsymbol{u}}_{i}}{\partial x_{j}}+\frac{\partial \tilde{\boldsymbol{u}}_{j}}{\partial x_{i}}\right)-\frac{\partial}{\partial x_{i}}\left(\overline{\rho \boldsymbol{u}_{i}^{\prime \prime} \boldsymbol{u}_{j}^{\prime \prime}}\right)+\bar{\rho} \boldsymbol{g}_{i}+S_{\mathrm{v}}$ & $(15)$ \\
\hline Energy & $\frac{\partial}{\partial x_{i}}\left(\bar{\rho} c_{\mathrm{g}} \tilde{\boldsymbol{u}}_{i} \tilde{T}\right)=\frac{\partial}{\partial x_{i}}\left[\left(\lambda+c_{\mathrm{g}} \frac{\mu_{\mathrm{t}}}{\operatorname{Pr}_{\mathrm{t}}}\right) \frac{\partial \tilde{T}}{\partial x_{i}}\right]+S_{\mathrm{h}}$ & $(16)$ \\
\hline Species & $\frac{\partial}{\partial x_{i}}\left(\bar{\rho} \tilde{\boldsymbol{u}}_{i} \tilde{Y}_{i}\right)=\frac{\partial}{\partial x_{i}}\left[\left(\bar{\rho} D_{i, \mathrm{~m}}+\frac{\mu_{\mathrm{t}}}{S c_{\mathrm{t}}}\right) \frac{\partial \tilde{Y}_{i}}{\partial x_{i}}\right]+r_{i}+S_{i}$ & $(17)$ \\
\hline \multirow[t]{5}{*}{ Realizable $k-\varepsilon$ model } & $-\overline{\rho \boldsymbol{u}_{i}^{\prime \prime} \boldsymbol{u}_{j}^{\prime \prime}}=\mu_{\mathrm{t}}\left(\frac{\partial \tilde{\boldsymbol{u}}_{i}}{\partial x_{j}}+\frac{\partial \tilde{\boldsymbol{u}}_{j}}{\partial x_{i}}\right)-\frac{2}{3} \bar{\rho} k \delta_{i j}$ & $(18)$ \\
\hline & $\frac{\partial}{\partial x_{j}}\left(\bar{\rho} k \tilde{\boldsymbol{u}}_{j}\right)=\frac{\partial}{\partial x_{j}}\left[\left(\mu+\frac{\mu_{\mathrm{t}}}{\sigma_{\mathrm{k}}}\right) \frac{\partial k}{\partial x_{j}}\right]+G_{\mathrm{k}}+G_{\mathrm{b}}-\bar{\rho} \varepsilon-Y_{\mathrm{M}}+S_{\mathrm{k}}$ & (19) \\
\hline & $\frac{\partial}{\partial x_{i}}\left[\left(\mu+\frac{\mu_{\mathrm{t}}}{\sigma_{\varepsilon}}\right) \frac{\partial \varepsilon}{\partial x_{i}}\right]+\bar{\rho} C_{1} S \varepsilon-\bar{\rho} C_{2} \frac{\varepsilon^{2}}{k+\sqrt{v \varepsilon}}+C_{1 \varepsilon} \frac{\varepsilon}{k} C_{3 \varepsilon} G_{\mathrm{b}}+S_{\varepsilon}$ & $(20)$ \\
\hline & $C_{1}=\max \left[0.43, \frac{\eta}{\eta+5}\right], \eta=S \frac{k}{\varepsilon}, S=\sqrt{2 S_{i j} S_{i j}}$ & \\
\hline & $C_{1 \varepsilon}=1.44, C_{2}=1.9, \sigma_{\mathrm{k}}=1.0, \sigma_{\varepsilon}=1.2$ & \\
\hline
\end{tabular}

For particle phase

Mass

$$
\frac{\mathrm{d} m_{\mathrm{p}}}{\mathrm{d} t}=\frac{\mathrm{d} m_{\mathrm{w}}}{\mathrm{d} t}+\frac{\mathrm{d} m_{\mathrm{v}}}{\mathrm{d} t}+\frac{\mathrm{d} m_{\mathrm{c}}}{\mathrm{d} t}
$$

Momentum

$$
\begin{gathered}
m_{\mathrm{p}} \frac{\mathrm{d} \boldsymbol{u}_{\mathrm{p}}}{\mathrm{d} t}=\frac{1}{8} \pi d_{\mathrm{p}}^{2} \rho C_{\mathrm{D}}\left|\boldsymbol{u}-\boldsymbol{u}_{\mathrm{p}}\right|\left(\boldsymbol{u}-\boldsymbol{u}_{\mathrm{p}}\right)+\frac{1}{6} \pi d_{\mathrm{p}}^{3}\left(\rho_{\mathrm{p}}-\rho\right) g \\
C_{\mathrm{D}}=\frac{24}{\operatorname{Re}}\left(1.0+0.15 \mathrm{Re}^{0.687}\right)
\end{gathered}
$$

Energy

$$
\begin{gathered}
m_{\mathrm{p}} c_{\mathrm{p}} \frac{\mathrm{d} T_{\mathrm{p}}}{\mathrm{d} t}=h A_{\mathrm{p}}\left(T-T_{\mathrm{p}}\right)+A_{\mathrm{p}} \varepsilon_{\mathrm{p}} \sigma\left(\theta_{\mathrm{R}}^{4}-T_{\mathrm{p}}^{4}\right)+m_{\mathrm{w}} h_{\mathrm{w}}+m_{\mathrm{v}} h_{\mathrm{v}}-\sum_{i} m_{\mathrm{c}, i} Q_{i} \\
\mathrm{Nu}=\frac{h d_{\mathrm{p}}}{\lambda_{\mathrm{g}}}=2.0+0.6 \operatorname{Re}^{1 / 2} \operatorname{Pr}^{1 / 3} \\
\theta_{\mathrm{R}}=\left(\frac{I}{4 \sigma}\right)^{1 / 4} \\
-\nabla \cdot q_{\mathrm{r}}=a G-4 a \sigma T^{4} \\
q_{\mathrm{r}}=-\frac{1}{3\left(a+\sigma_{\mathrm{s}}\right)-C \sigma_{\mathrm{s}}} \nabla G \\
G=\int_{\Omega=4 \pi} I d \Omega
\end{gathered}
$$




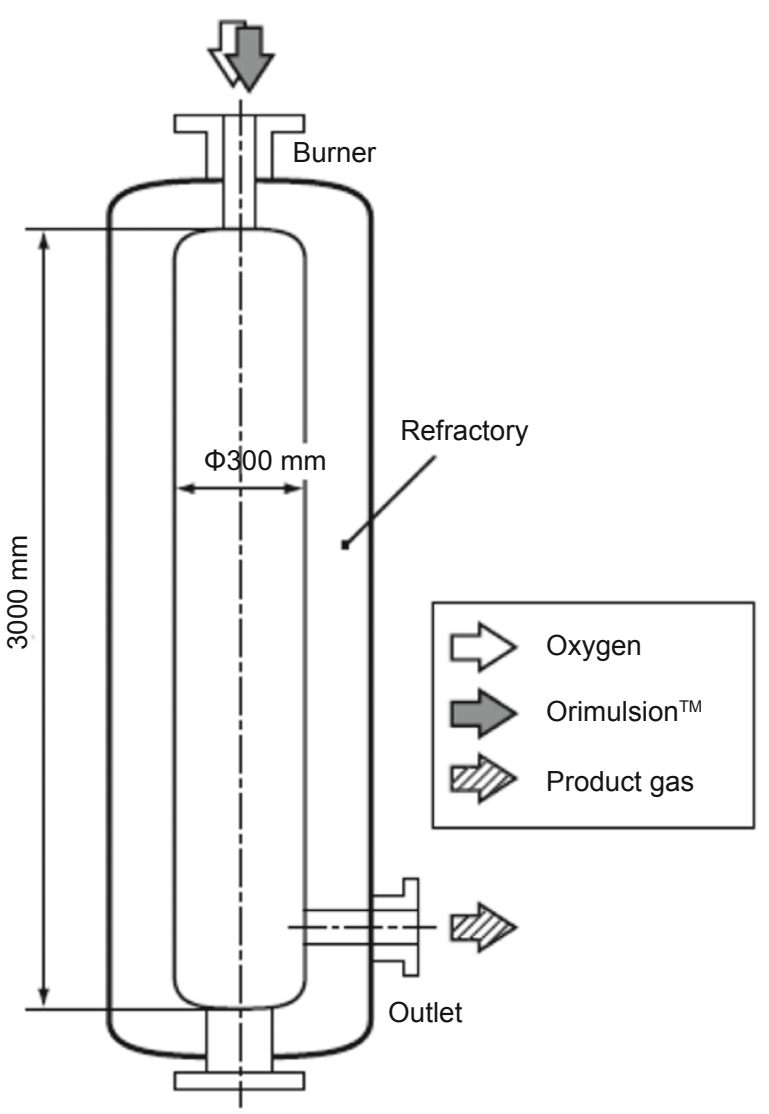

Fig. 2 Experimental setup of orimulsion gasification in an entrained flow gasifier

Table 4 Properties of orimulsion

\begin{tabular}{ccccc}
\hline \multicolumn{2}{c}{ Proximate analysis (wet), wt $\%$} & & \multicolumn{2}{c}{ Ultimate analysis (dry), wt $\%$} \\
${$\cline { 1 - 2 }$} }$ & 12.84 & & $\mathrm{C}$ & 84.28 \\
Volatile & 58.18 & & $\mathrm{H}$ & 10.33 \\
Moisture & 28.80 & $\mathrm{~S}$ & 3.95 \\
Ash & 0.18 & & $\mathrm{O}$ & 0.55 \\
Heating value, $\mathrm{MJ} / \mathrm{kg}$ & 29.77 & $\mathrm{~N}$ & 0.64 \\
\hline
\end{tabular}

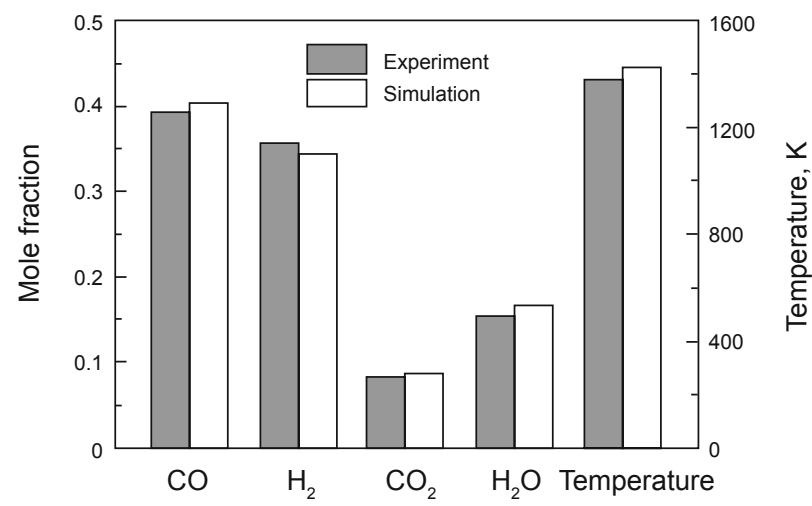

Fig. 3 Comparison between simulation and experimental results

asphalt water slurry and the orimulsion, the developed CFD model can be employed to predict the gasification performance of the asphalt water slurry.

\section{Gasification performance of asphalt water slurry}

The proximate analysis and ultimate analysis data of asphalt particles are shown in Table 5. The asphalt particles were made into water slurry with $35 \mathrm{wt} \%$ water (Liu, 2009). For comparison with the orimulsion gasification process, the gasification of asphalt water slurry in the same gasifier under the same operating conditions was simulated. The operating pressure is $1.9 \mathrm{MPa}$, and the flow rate of asphalt water slurry and oxygen are $85 \mathrm{~kg} / \mathrm{h}$ and $65.6 \mathrm{~kg} / \mathrm{h}$, respectively, which correspond to an oxygen equivalence ratio of 0.40 . The size distribution of asphalt droplets after atomization is assumed to be the same as the size distribution of asphalt particles as shown in Fig. 4 (Liu, 2009), and it follows a Rosin-Rammler distribution with $d_{\mathrm{av}}=43 \mu \mathrm{m}$ and $n=0.87$.

Table 5 Properties of asphalt particles

\begin{tabular}{ccccc}
\hline \multicolumn{2}{c}{ Proximate analysis (wet), wt $\%$} & & \multicolumn{2}{c}{ Ultimate analysis (dry), wt $\%$} \\
${$\cline { 1 - 2 }$} }$ & 29.84 & & $\mathrm{C}$ & 86.58 \\
Volatile & 69.08 & & $\mathrm{H}$ & 8.53 \\
Moisture & 0.33 & $\mathrm{~S}$ & 0.66 \\
Ash & 0.75 & $\mathrm{O}$ & 1.98 \\
Heating value, $\mathrm{MJ} / \mathrm{kg}$ & 38.82 & $\mathrm{~N}$ & 2.14 \\
\hline
\end{tabular}

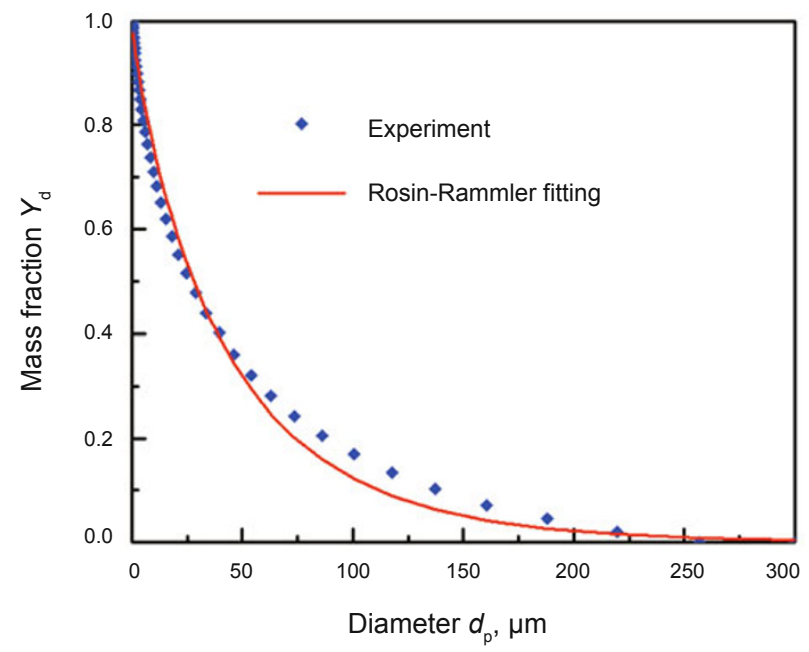

Fig. 4 Size distribution of asphalt particles

\subsection{Flow field, temperature, and composition distributions}

The flow field and temperature distributions are shown in Fig. 5. Pure oxygen is injected into the gasifier through the nozzle in order to atomize the asphalt water slurry into small droplets, which leads to a jet flow region with high velocity and intense turbulence at the top of the gasifier, as shown in Fig. 5(a, b and c). The reflux region is formed around the jet flow region due to the entrainment effect of jet flow, and other areas can be categorized into plug flow region. Fig. 6 


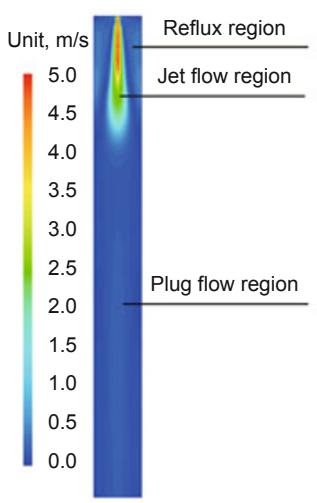

(a)

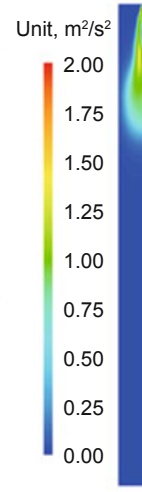

(b)

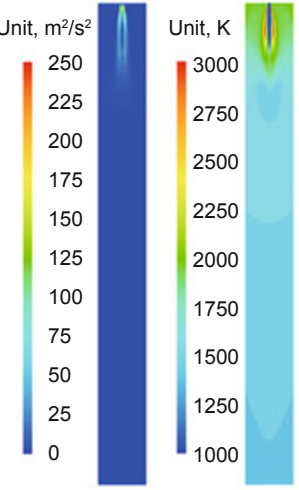

(d)

$\varepsilon$ Temperature
Fig. 5 Flow field and temperature distributions presents the reaction rate of main reactions, which exclude the reactions consuming $\mathrm{C}_{6} \mathrm{H}_{6}$ and $\mathrm{CH}_{4}$ because of their extremely low concentration. Clearly, all the reactions mainly occur in the jet flow region, and the reaction rates of combustion reactions (Reaction 3, 8, and 9) are much faster than those of gasification reactions (Reaction 4, 5, and 12). In the jet flow region, the combustible species, such as $\mathrm{CO}, \mathrm{H}_{2}$, and $\mathrm{C}$, react with oxygen rapidly (Figs. 6a, 6b, and 6c) to form a high temperature flame (Fig. 5d) because of the intense exothermic effect. The distributions of species mole fraction are shown in Fig. 7. Due to the fast combustion reactions, $\mathrm{CO}$ and $\mathrm{H}_{2}$ mole fraction are extremely low in the jet flow region, while the mole fraction of the products $\left(\mathrm{CO}_{2}\right.$ and $\left.\mathrm{H}_{2} \mathrm{O}\right)$ are very high in this region. The high $\mathrm{H}_{2} \mathrm{O}$ concentration should also be attributed to the water evaporation and boiling of asphalt-

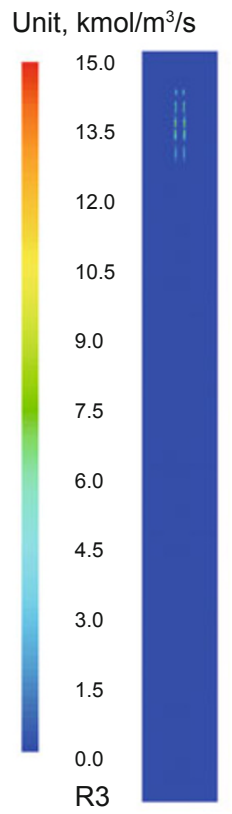

(a)

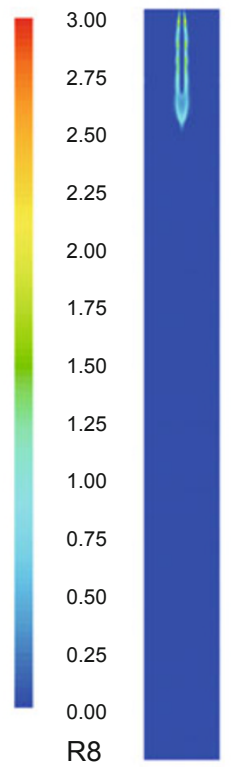

(b)

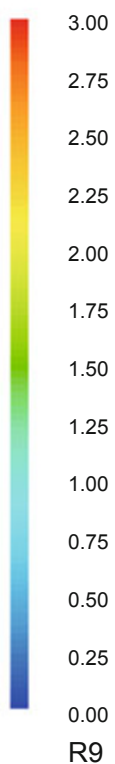

(c)

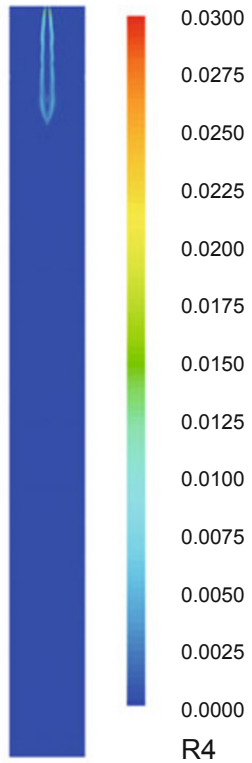

R4

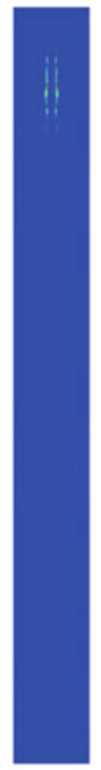

(d)

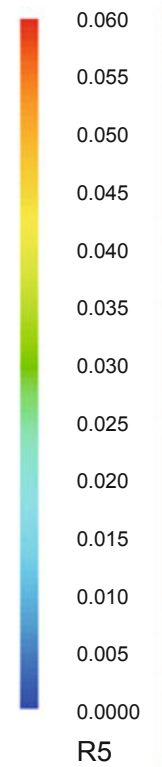

R5 (e)

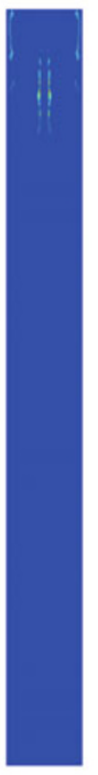

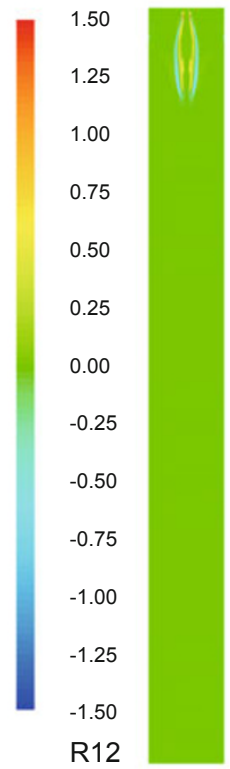

(f)

Fig. 6 Reaction rates of main reactions
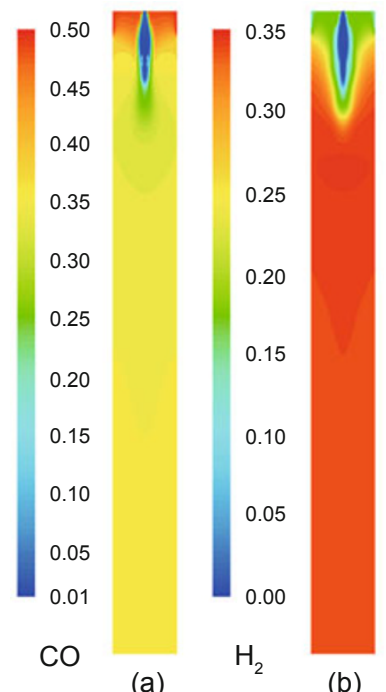

(b)
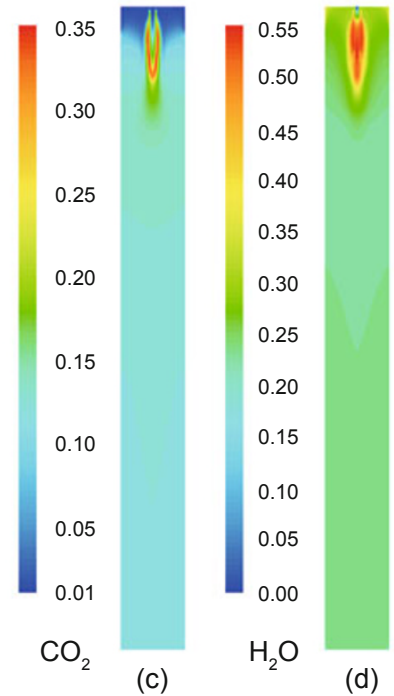

(d)

Fig. 7 Species mole fraction distributions

water droplets. Because all the reactions mainly occur in the jet flow region, the temperature and species mole fraction change very slightly in the lower region of the gasifier.

Table 6 shows the predicted species mole fraction and temperature at the outlet of gasifier as well as the carbon conversion in the gasification processes of the asphalt water slurry and the orimulsion, respectively. Compared with the gasification result of the orimulsion, the gasification of asphalt water slurry leads to low $\mathrm{CO}$ and $\mathrm{H}_{2}$ mole fractions, temperature and carbon conversion, but high $\mathrm{CO}_{2}$ and $\mathrm{H}_{2} \mathrm{O}$ mole fractions, which may due to the high water and fixed carbon contents and low heating value of the asphalt water slurry. Table 6 shows that the gasification of asphalt water slurry can result in a syngas $\left(\mathrm{CO}+\mathrm{H}_{2}\right)$ content of $70.7 \%$ and a carbon conversion of $87.3 \%$. The gasification performance of the asphalt slurry is a little worse than that of the orimulsion. For the gasification of coal-water slurry, the syngas content is only about $60 \%$ under same conditions due to the high ash and oxygen content in the coal particles (Wu et al, 2010). 
Anyway, the simulation results indicate that the asphalt water slurry is a good feedstock for gasification.

Table 6 Predicted gasification results of orimulsion and asphalt water slurry

\begin{tabular}{ccccccc}
\hline Item & $\mathrm{CO}, \%$ & $\mathrm{H}_{2}, \%$ & $\mathrm{CO}_{2}, \%$ & $\mathrm{H}_{2} \mathrm{O}, \%$ & $T, \mathrm{~K}$ & Carbon conversion, \% \\
Orimulsion & 40.2 & 34.5 & 8.6 & 16.7 & 1415 & 94.8 \\
$\begin{array}{c}\text { Asphalt } \\
\text { water slurry }\end{array}$ & 38.1 & 32.6 & 10.0 & 19.3 & 1404 & 87.3 \\
\hline
\end{tabular}

\subsection{Particle trajectories, residence time, and carbon} conversion

The carbon conversion, an important parameter to evaluate the gasifier performance, is affected by the motion and size of particles. Fig. 8 illustrates the trajectories of the particles with different sizes in the gasifier, which are colored by the residence time. After being fed into the gasifier, the particles firstly follow the jet flow, and then some particles are entrained into the reflux region and merged into the jet flow again due to the turbulence effects, and some particles flow along the plug flow region and directly flow out of the gasifer. The reflux of some particles increases the particle residence time, especially in the jet flow region where the consumption reactions of carbon (Reaction 3, 4, and 5) take place. Therefore, the reflux greatly improves the carbon conversion. The amount of the particles entrained into the reflux region is influenced by the particle size. As shown in Fig. 8, the amount of particles being recirculated in the reflux region decreases with an increase of particle size. The average residence time and carbon conversion for different particle sizes are shown

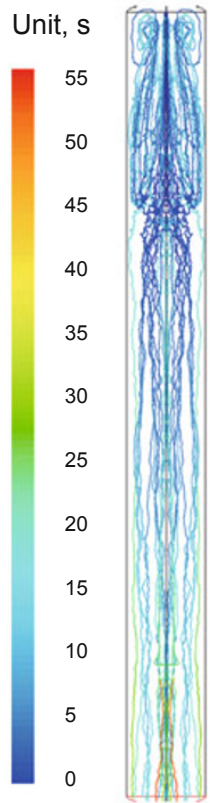

(a)

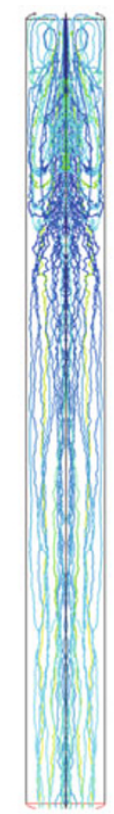

(b)

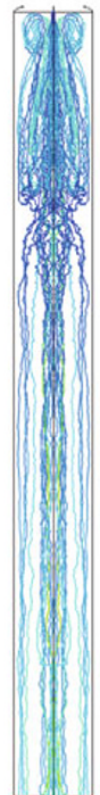

(c)

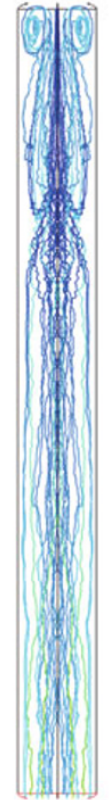

(d)

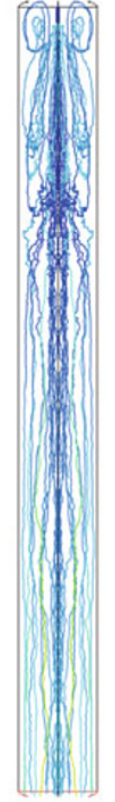

(e)
$25 \mu \mathrm{m} \quad 50 \mu \mathrm{m} \quad 75 \mu \mathrm{m} \quad 100 \mu \mathrm{m} \quad 125 \mu \mathrm{m}$ in Table 7. With an increase of particle size, the averaged residence time decreases due to the lower recirculation in the reflux region. Moreover, larger particles contain more carbon on the surface. Therefore, the average carbon conversion decreases with an increase of particle size.

Table 7 Effects of particle size on the residence time and carbon conversion

\begin{tabular}{cccccc}
\hline Particle size $d_{\mathrm{p}}, \mu \mathrm{m}$ & 25 & 50 & 75 & 100 & 125 \\
\hline Averaged residence time, s & 21.3 & 18.1 & 16.3 & 14.0 & 13.5 \\
Averaged carbon conversion, \% & 91.5 & 88.3 & 85.4 & 78.2 & 78.9 \\
\hline
\end{tabular}

4.3 Effects of oxygen equivalence ratio and mass content of asphalt particles in water slurry on gasification performance

The effects of the oxygen equivalence ratio on the predicted species mole fraction, temperature, carbon conversion, and cold gas efficiency are shown in Table 8. With the increase of the equivalence ratio from 0.40 to 0.44 , the combustion reactions are favored as more $\mathrm{O}_{2}$ is fed into the gasifier, which means more combustible species are combusted and leads to higher temperature and lower $\mathrm{H}_{2}$ mole fraction. A higher temperature promotes the gasification reactions of carbon, hence the carbon conversion and $\mathrm{CO}$ mole fraction increases. In addition, the water-shift reaction is suppressed at a higher temperature, which leads to lower $\mathrm{CO}_{2}$ and higher $\mathrm{H}_{2} \mathrm{O}$ mole fraction. The cold gas efficiency reaches a minimum at 0.42 as the equivalence ratio increases.

Table 8 Effects of equivalence ratio on the gasification performance

\begin{tabular}{ccccc}
\hline Equivalence ratio & 0.40 & 0.42 & 0.43 & 0.44 \\
\hline $\mathrm{CO}, \%$ & 38.1 & 38.2 & 38.6 & 38.9 \\
$\mathrm{H}_{2}, \%$ & 32.6 & 29.9 & 29.4 & 28.9 \\
$\mathrm{CO}_{2}, \%$ & 10.0 & 9.9 & 9.6 & 9.3 \\
$\mathrm{H}_{2} \mathrm{O}, \%$ & 19.3 & 21.9 & 22.1 & 23.0 \\
Temperature, $\mathrm{K}$ & 1404 & 1516 & 1558 & 1611 \\
Carbon conversion, \% & 87.3 & 88.5 & 89.4 & 91.1 \\
Cold gas efficiency, \% & 71.1 & 69.3 & 69.8 & 70.9 \\
\hline
\end{tabular}

Table 9 shows the predicted results of the effects of the mass concentration of asphalt particles in asphalt water slurry on the gasification performance. With an increase of the mass content of asphalt particles, the asphalt water slurry, which is fed into the gasifier, has less water and more asphalt. Therefore, after gasification of the asphalt water slurry, the $\mathrm{H}_{2} \mathrm{O}$ and $\mathrm{CO}_{2}$ mole fractions decrease, while the $\mathrm{CO}$ mole fraction and temperature increases. However, the $\mathrm{H}_{2}$ mole fraction changes very slightly, because high temperature can promote the reverse water-shift reaction which restrains the $\mathrm{H}_{2}$ production. In addition, although the temperature increases with the increase of mass content of asphalt particles, the 
carbon conversion and cold gas efficiency change very slightly.

Table 9 Effects of mass content of asphalt particles in asphalt water slurry on the gasification performance

\begin{tabular}{cccccc}
\hline $\begin{array}{c}\text { Mass content of asphalt particles } \\
\text { in asphalt water slurry, \% }\end{array}$ & 60.0 & 62.5 & 65.0 & 67.5 & 70.0 \\
\hline $\mathrm{CO}, \%$ & 35.5 & 36.8 & 38.2 & 39.9 & 41.6 \\
$\mathrm{H}_{2}, \%$ & 29.9 & 30.0 & 29.9 & 30.1 & 30.8 \\
$\mathrm{CO}_{2}, \%$ & 10.4 & 10.1 & 9.9 & 9.4 & 8.7 \\
$\mathrm{H}_{2} \mathrm{O}, \%$ & 24.2 & 23.1 & 21.9 & 20.6 & 18.9 \\
Temperature, $\mathrm{K}$ & 1504 & 1510 & 1516 & 1530 & 1537 \\
Carbon conversion, \% & 88.2 & 89.3 & 88.5 & 88.6 & 89.3 \\
Cold gas efficiency, \% & 69.5 & 70.3 & 69.3 & 69.5 & 71.1 \\
\hline
\end{tabular}

\section{Conclusions}

A three-dimensional CFD model based on an EulerianLagrangian approach was developed to predict the gasification behavior in an entrained flow gasifier. The CFD model was validated by orimulsion gasification experiments in an entrained flow gasifier reported by Watanabe et al. (2002). The predicted temperature and species mole fraction at the outlet of the gasifier agreed well with experimental data. Then the gasification behavior of an asphalt water slurry in the same gasifier at similar operating conditions was simulated. In the gasifier, all the reactions mainly occur in the jet flow region, and the temperature and species mole fraction distributions change slightly in other regions. Both the average residence time and carbon conversion of asphalt particles decrease with an increase of particle size. A higher equivalence ratio and mass content of asphalt particles in asphalt water slurry both lead to a higher temperature and better carbon conversion. The predicted results indicated that the asphalt water slurry was a good feedstock for gasification with a high syngas content and carbon conversion. These results provide a guideline for further experimental study and the commercial application of asphalt water slurry gasification technology.

\section{Acknowledgements}

The authors acknowledge the support by the National Basic Research Program (Grant No. 2010CB226906) and the Science Foundation of China University of Petroleum, Beijing (No. KYJJ2012-03-01). The authors also thank the anonymous referees for their comments on this manuscript.

\section{Symbols}

$\begin{array}{ll}a & \text { Absorption coefficient, } \mathrm{L} / \mathrm{m} \\ A & \text { Empirical constant } \\ A_{0} & \text { Pre-exponential factor } \\ A_{\mathrm{p}} & \text { Particle surface area, } \mathrm{m}^{2}\end{array}$

$B$

$c_{\mathrm{g},} c_{\mathrm{p}} \quad$ Heat capacity of gas and particle, $\mathrm{J} /(\mathrm{kg} \cdot \mathrm{K})$

$C$ Linear-anisotropic phase function coefficient

$C_{j, s} \quad$ Diffusion rate constant

$C_{\mathrm{D}} \quad$ Drag coeffi cient, $\mathrm{kg} /\left(\mathrm{m}^{3} \cdot \mathrm{s}\right)$

$d_{\mathrm{av}} \quad$ Averaged particle diameter, $\mu \mathrm{m}$

$d_{\mathrm{p}} \quad$ Particle diameter, $\mu \mathrm{m}$

$D_{i, \mathrm{~m}} \quad$ Diffusion coefficient of species $i$ in the gas mixture, $\mathrm{m}^{2} / \mathrm{s}$

$D_{j, s} \quad$ Diffusion rate coefficient

G

$g$

$h$

$h_{\mathrm{w}}, h_{v}$

I

$k$

$k_{0}$

$k_{c}$

$m_{\mathrm{p}}$

$m_{\mathrm{v}}$

$m_{\mathrm{w}}$

$m_{\mathrm{w}}$

$n$

$\mathrm{Nu}$

$P$

$Q$

$q_{\mathrm{r}}$

$R$

$r$

$\operatorname{Re}$

$S$

$\mathrm{Sc}$

$\mathrm{Sh}$

$T, T_{\mathrm{p}}$

$t$

$u, u_{\mathrm{p}} \quad$ Gas and particle velocity, $\mathrm{m} / \mathrm{s}$

$v_{i, r}^{\prime}, v_{i, r}^{\prime \prime} \quad$ Stoichiometric coefficient for reactant and product $i$ in reaction $r$ 
$x \quad$ Mass fraction of produced volatile

$x_{\infty} \quad$ Final volatile yield

$Y_{\mathrm{d}} \quad$ Mass fraction of droplets of diameter greater than $d_{\mathrm{p}}$

$Y_{\mathrm{p}}, Y_{\mathrm{R}} \quad$ Mass fraction of product species and reactant species

\section{Greek letters}

$\begin{array}{ll}\alpha & \text { Mass fraction } \\ \beta & \text { Temperature exponent } \\ \theta_{\mathrm{R}} & \text { Radiation temperature, } \mathrm{K} \\ \sigma & \text { Stefan-Boltzmann constant, } \mathrm{W} /\left(\mathrm{m}^{2} \cdot \mathrm{K}^{4}\right) \\ \sigma_{\mathrm{s}} & \text { Scattering coefficient, } 1 / \mathrm{m} \\ \lambda & \text { Thermal conductivity, } \mathrm{W} /(\mathrm{m} \cdot \mathrm{K}) \\ \varepsilon & \text { Dissipation rate of turbulence kinetic energy, } \\ & \quad \mathrm{m}^{2} / \mathrm{s}^{3} \\ \mu & \text { Viscosity, Pa } \cdot \mathrm{s} \\ \rho, \rho_{\mathrm{p}} & \text { Gas and particle density, } \mathrm{kg} / \mathrm{m}^{3} \\ \Omega & \text { Solid angle }\end{array}$

\section{Subscripts}

$\begin{array}{ll}i, j & \text { Species or coordinate index } \\ \mathrm{t} & \text { Turbulence }\end{array}$

\section{References}

Ashizawa M, Hara S, Kidoguchi K, et al. Gasification characteristics of extra-heavy oil in a research-scale gasifier. Energy. 2005. 30(11-12): 2194-2205

Bustamante F, Enick R M, Killmeyer R P, et al. Uncatalyzed and wallcatalyzed forward water-gas shift reaction kinetics. AIChE Journal. 2005. 51(5): 1440-1454

Chen C, Horio M and Kojima T. Use of numerical modeling in the design and scale-up of entrained flow coal gasifiers. Fuel. 2001.
80(10): 1513-1523

Harris D J and Smith I W. Intrinsic reactivity of petroleum coke and brown coal char to carbon dioxide, steam and oxygen. Symposium (International) on Combustion. 1991. 23(1): 1185-1190

Gong J S, Fu W B and Zhong B J. A study on the pyrolysis of asphalt. Fuel. 2003. 82(1): 49-52

Jones W P and Lindstedt R P. Global reaction schemes for hydrocarbon combustion. Combustion and Flame. 1988. 73(3): 233-249

Kuo K K Y. Principles of Combustion. New York: John Wiley and Sons. 1986

Liu X. Study on the Pitch-Water Slurry Prepared by Powdered Asphalts with High Softening Point. Master Thesis. China University of Petroleum-Beijing. 2009 (in Chinese)

Magnussen B F and Hjertager B H. On mathematical modeling of turbulent combustion with special emphasis on soot formation and combustion. Symposium (International) on Combustion. 1977. 16(1): 719-729

Patankar S V. Numerical Heat Transfer and Fluid Flow. Washington D C: Hemisphere. 1980

Ranz W E and Marshall W R. Evaporation from drops, Part I. Chemical Engineering Progress. 1952a. 48(3): 141-146

Ranz W E and Marshall W R. Evaporation from drops, Part II. Chemical Engineering Progress. 1952b. 48(4): 173-179

Sun Z, Dai Z, Zhou Z, et al. Numerical simulation of industrial opposed multiburner coal-water slurry entrained flow gasifier. Industrial \& Engineering Chemistry Research. 2012. 51(6): 2560-2569

Watanabe H, Otaka M, Hara S, et al. Modelling and simulation for extra heavy oil gasification on entrained flow gasifier. International Joint Power Generation Conference, 24-26 June 2002, Phoenix, AZ, USA. pp 667-674

Westbrook C K and Dryer F L. Simplified reaction mechanisms for the oxidation of hydrocarbon fuels in flames. Combustion Science and Technology. 1981. 27(1-2): 31-43

Wu Y, Zhang J, Smith P J, et al. Three-dimensional simulation for an entrained flow coal slurry gasifier. energy \& Fuels. 2010. 24(2): 1156-1163

$\mathrm{Xu}$ Y. Industrial experiments on deoiled asphalt gasification under high softening point conditions. Sino-Global Energy. 2010. 15(3): 92-96 (in Chinese)

Zhao S, Xu C, Wang R, et al. Deep separation method and processing system for the separation of heavy oil through granulation of coupled post-extraction asphalt residue. US Patent 7597794, 2009

(Edited by Zhu Xiuqin) 